\title{
الإبداع الإداري بين النظرية والتطبيق لدي العاملين برعاية الطلاب
}

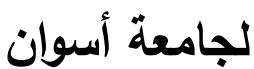

* 1 * •د/عادل محمد عبدالمنعم مكي

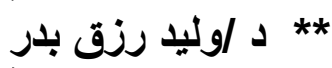

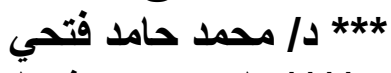

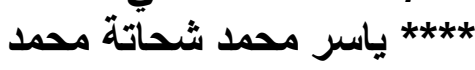

\section{مقدمة ومشكلة البحث:}

مع بداية القرن الحادي والعشرين والجميع يعيش وسط متغيرات وتحديات عديدة ومتلاحقة في شتى مجالات الحياة، فمعدلات التغيير في نتزايد مستمرة والأعمال تتوجه بصورة ملحوظة إلى العالمية وفى كل يوم تزداد ظهور التكنولوجيا الجديدة المتطورة والقوى العاملة تصبح أكثر تتوعاً من حيث المعرفة والمهارة.(1 (1 ج 1 ) وتتميز الإدارة الحديثة بملامح أساسية تمثل فى توجيه جهود الإدارة وأنشطتها على تحقيق رضا العملاء واستثمار الطاقات الخلاقة والقوى البشرية وذلك لأن البشر

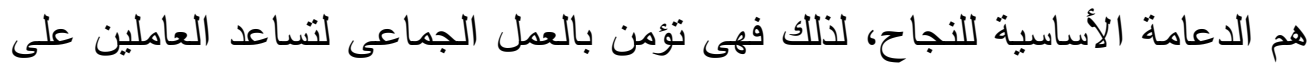
الإبتكار والإبداع والمشاركة الجادة فى تحقيق مستوى اكبر من التميز والتقوق من خلال نظم محددة وموضوعة بإحكام، كما يتم إتخاذ القرارات بناء على جمع وإستخدام البيانات المعتمدة على الملاحظة والخبرة والتجربة ليتم الإستفادة من الحقائق فى عملية

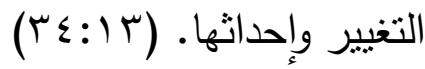

* أستاذ الإدارة الرياضية وعميد كلية التربية الرياضية -جامعة أسوان

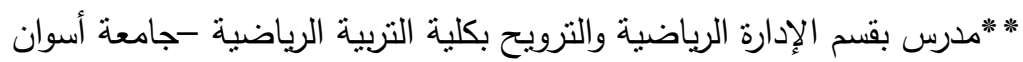
* * * * * *رس بقسم الإدارة الرياضية والترويح بكلية التربية الرياضية -جامعة أسوان ***** **رير عام العلاقات العامة بمستشفيات أسوان الجامعي وامين كلية التربية الرياضية 
لذلك ينبغي تقدير اهمية دور الإبداع الإداري من خلا جهود ملحوظة لتوفير

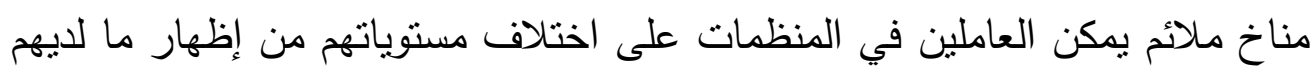
من قدرات إبداعية واستغلالها الإستغلال الأمنل بما ينعكس إيجاباً على روحهم المعنوية حيث يمكن أن يؤدي بهم إلى الحماس للعمل والبحث عن حلول للمشكلات التي تواجهم بصورة إبداعية، مما يدفع النمو والتطوير للمنظمات والارتقاء بمستوى الأداء

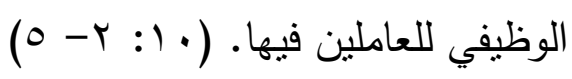

ويري الباحث أن الأبداع الإداري أثنار الباحثين والمفكرين في حقل الإدارة ذلك لأن العامل البشري هو المحور الحقيقي له في المنظمات الإدارية، كما أنه يعتبر أحد الإداري النارين

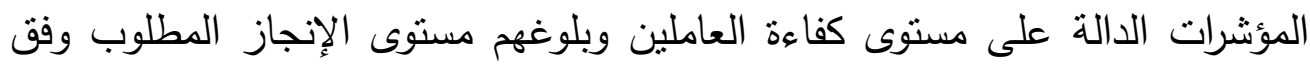

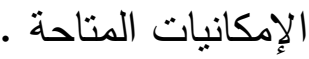

حيث يشير جميس بيكر James Becker ( ( . -rم) إلى أن الأداء الفردي أو الأداء الوظيفي هو أهم محاور فاعلية الأداء الكلى للمنظمة، وذلك يتطلب ضرورة اهتمام واعتناء كافة المديرين في جميع المستويات التنظيمية بتطوبر وتتمية أداء المرؤوسين من حيث الكمية والجودة حيث ينعكس ذللك بالضرورة على أداء جماعات العمل والنتيجة أو المحصلة النهائية هي فاعلية أداء المنظمة ككل. (0 (: ج1،، .9) وترى "راوية محمد حسن "(999 ام) أن محددات الأداء الوظيفي هي: الجهد، القدرات، إدراك الدور المهام ويشير "الجهد" الناتج من حصول الفرد على التدعيم الحوافز إلى الطاقة الجسمانية والعقلية، والتي يبذلها الفرد لأداء مهمته، أمسا "القدرات" فهي الخصائص الثخصية المستخدمة لأداء الوظيفة، ولا تتغير وتتقلب هذه وله

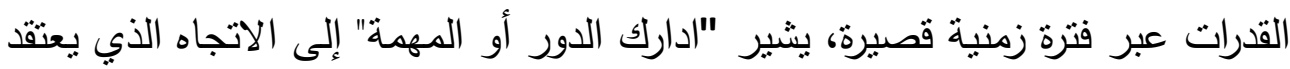

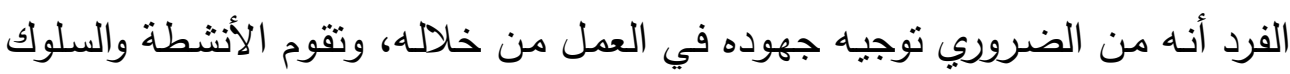

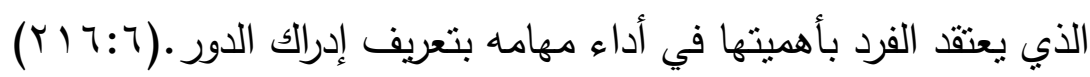


وتواجه مؤسسات التعليم العالي العديد من المشكلات والتحديات في ظل العولمة وثورة المعلومات والإتصالات والتقلبات العالمية في عالم الإقتصاد وإنعكاساته على سوق العمل ، وهي مطالبة بقيادة التغيير في المجتمع نحو الآمال والطموحات المرجوة، مما يفرض عليها تغيير أساليبها الإدارية الحالية ، وتنبي مفاهيم إدارية جديدة ، تمكنها من وهن زيادة كفاءتها ، وجودة مخرجاتها لتصبح بمستوى التحديات والآمال التتموية. (ع : بـ) وكان الخطيب من أثند المنتقدين للإدارة الجامعية في الوطن العربي حينما أكد

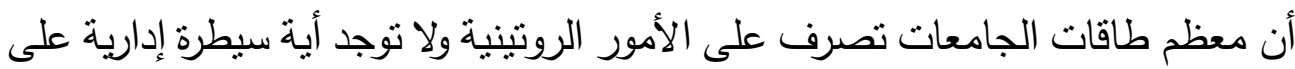

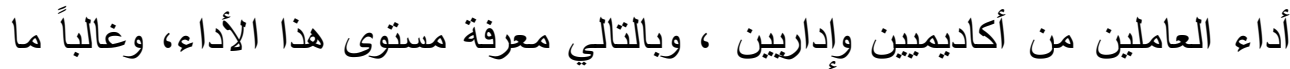
تستخدم أساليب مراوغة وتأخير لمقاومة الإصلاح والتغيير • (1 : بr) وتعد الجامعة من أحد هذه المنظمات التي تقوم بالدور الإيجابي، حيث تعمل على رعاية الطلاب في المجتمع لتقديم عدة خدمات مهنية ومجهودات ذات صبغة وقائية وإنشائية واجتماعية ورياضية، تهدف إلى تكامل بناء شخصية أبناءنا وتزويدهم

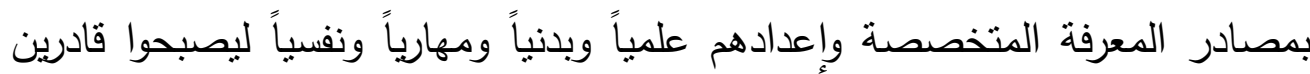
على مواكبة مستحدثات العصر • ومن خلال عمل الباحث بجامعة أسوان وتقلاه العديد من المناصب الإدارية بها ومن خلال المقابلات الثخصية المبدئية والغير مقننة مع عدد من العاملين بجامعة أسوان، لاحظ أن هناك تباطئ من قبل بعض العاملين في أنجاز المهام الموكلة إليهم من قبل الإدارة العليا، كما يوجد هناك قصور في أداء بعض العاملين بالنواحي الإدارية بالجامعة، كما لا يوجد لايهم الدافع والرغبة لتحقيق الأهداف التى وجدت من أجلها الجامعة ألا وهو الأرتقاء بالمنظومة التعليمية، كما يوجد تمسك من قبل بعض العاملين بالنواحي الروتينية التى أصبحت أيضاً عائقاً نحو تحقيق الأهداف الاستراتيجية بالجامعة، وكذلك معارضة بعض العاملين بالجامعة لتبني الأفكار الإبداعية المتطورة الجديدة ورفضهم التام لعملية التفكير الإبداعي الذي يعمل بدوره على أحداث تغيرات جديدة في المنظومة الإدارية داخل الجامعة، وقد يرجع الباحث ذللك إلي اعتماد 
العاملين في العمل على إتجاهات إدارية تقليدية، وعدم تزويد هؤلاء العاملين بالدورات

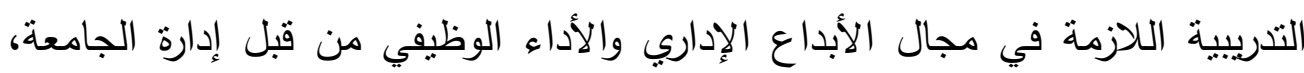
الأمر الذي يؤدي بدوره لعدم الدراية الكافية من قبل بعض العاملين بالجامعة بماهية

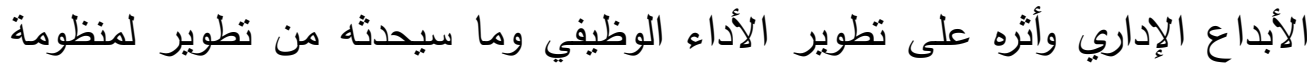
العمل داخل الجامعة، وهذا ما أشنارت إليه نتائج العديد من الدراسات كدراسة والتي الأي أجريت في الأبداع الإداري والتي ثبتت نتائجها أن الاعتماد على الاتجاهات الإدارية

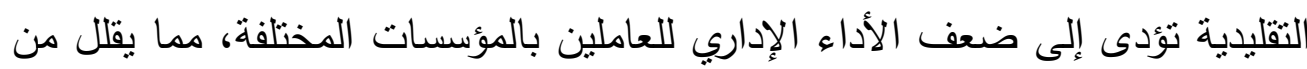

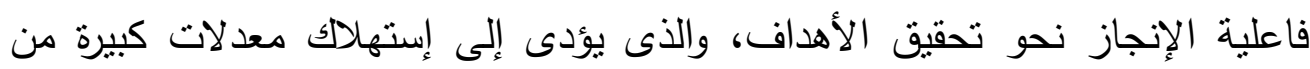

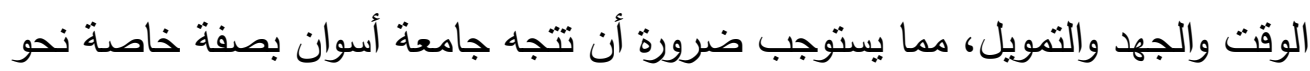

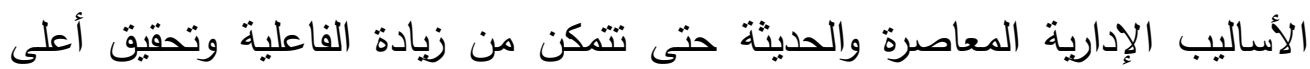
مستوى ممكن من الإنجاز على مختلف المستويات المحلية والدولية.

هذا مما دفع الباحث إلى إجراء هذا البحث كمحاولة منه لمعرفة واقع الإبداع الإداري بين النظري والتطبيق للعاملين برعاية الطلاب لجامعة أسوان، ليكون منطلق لتميز العمليات الإداربة بجامعة أسوان. هدف البهث : يهدف البحث إلى التعرف علي الإبداع الإداري لدي العاملين برعاية الطلاب لجامعة • أسوان تصساؤل البهـ :

1- هل يمكن تطوير الإبداع الإداري للعاملين برعاية الطلاب جامعة أسوان؟

الهصطلحات الواردة في البحث:

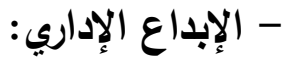


عبارة عن مجموعة العمليات التي يستخدما الإنسان بما هو متوفر لليه من قدرات

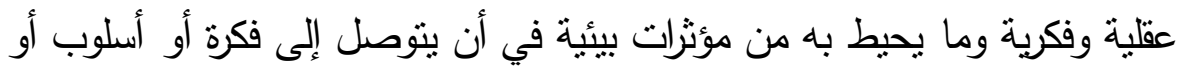
نظرية أو منتج بحيث يحقق النفع للمجتمع أو للمنشأة التي يعمل فيها. (1 : 7 (1)

\section{الدراسات السابقة:

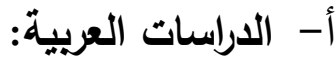

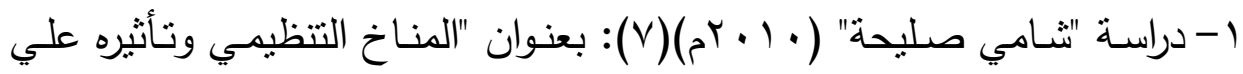
الأداء الوظيفي للعـاملين " واستهدفت الدراسـة التعرف علي المنـاخ التنظيمي وتأثيره علي الأداء الوظيفي للعاملين، واستخدم الباحث المنهج الوصفي، وتم اختيار عينة الدراسة من الإتحاد المصري لتنس الطاولة وفروعه ويتكون من أعضاء مجلس إدارة الإتحاد والفروع التابعة له من العاملين بالإتحاد وفروعه الإسه وكذلك من المستقيدين من خدمات الإتحاد من لاعبين وحكام ومدربين وإداريين

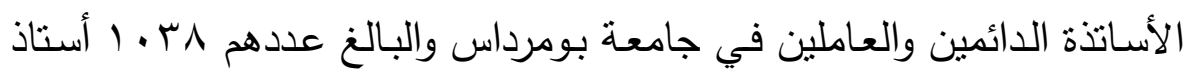

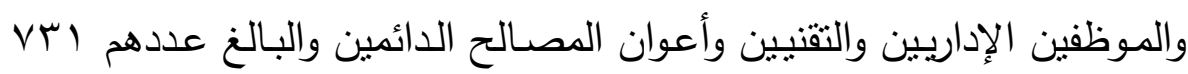
موظف، وكانت أهم النتائج أنـه هنـاك شـور محايد أو معتدل لـدى معظم الموظفين الإداريين على المنـاخ التظظيسي السـائد وهنالك تصسور سـلبي لدى معظم الأساتذة على المناخ التظظيمي.

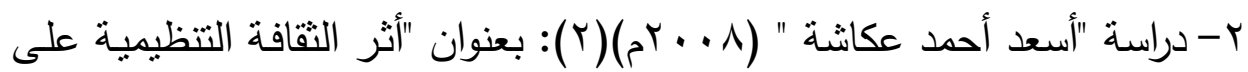

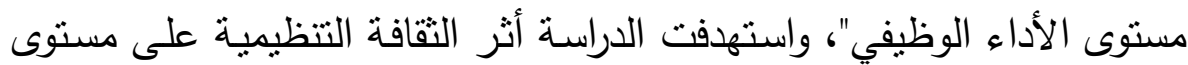
الأداء الوظيفي، واستخدم الباحث المنهج الوصفي، وتم اختيار مجتمع الدراسة

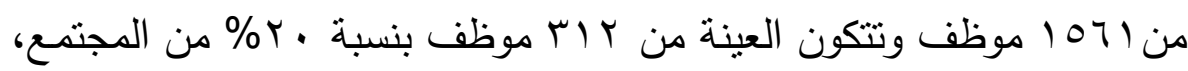

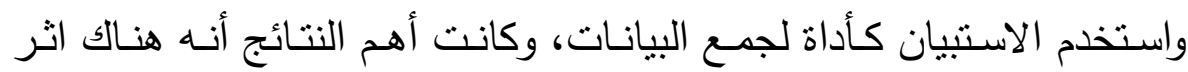

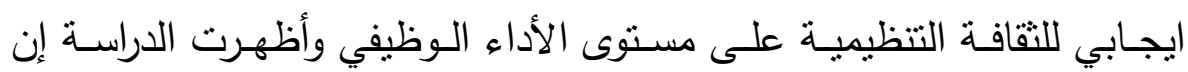


العـاملين بحاجـة إلى تطـوير مسـتوى المهـارات والقدرات المتعلقـة بالجوانـب الإبداعية والإبتكارية.

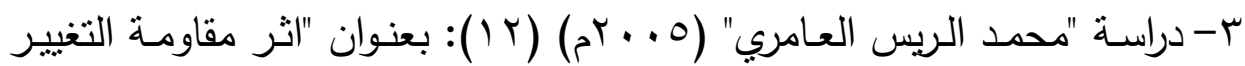
على فاعلية الأداء الوظيفي بالتطبيق على شركة العين لتوزبع الكهرباء والماء بدولة الإمارات العربية المتحدة " واستهدفت الدراسة التعرف على العوامل التي تدعو إلى التغيير والتعـرف على الأسـباب التي تؤدى إلى مقاومـة التغييـر والتعرف على الأسباب التي تؤدى إلى مقاومة التغيير والتعرف على مؤشرات

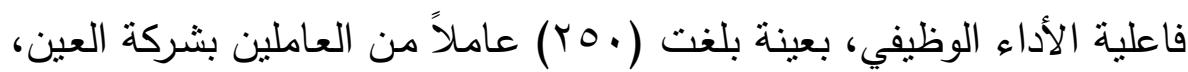

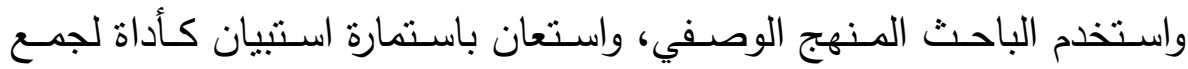
البيانات، وكانت أهم النتائج أنه لا توجد اختلافات معنوية بين الذكور والإناث من حيث أي بعد أو سبب من أسباب مقاومة التغيير لا توجد اختلافات معنوية

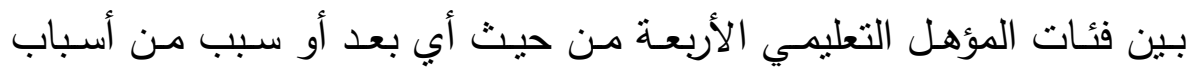

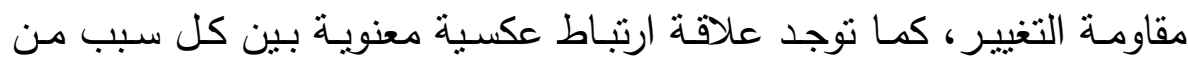
أسباب مقاومـة التغيير وبين كل مؤشـر من مؤشـرات فاعلية الأداء الوظيفي الخمسة.

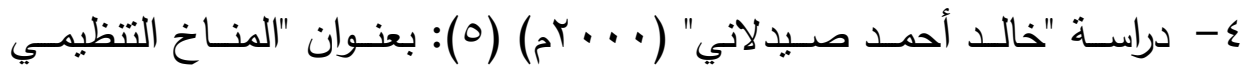

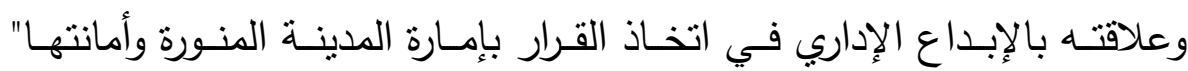

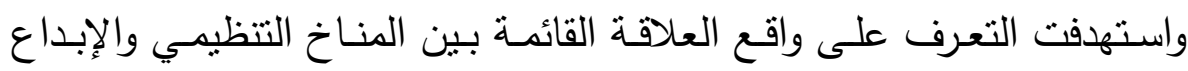
الإداري في إتخـاذ القرارات، واستخدم المنهج الوصفي، واشتملت العينـة على

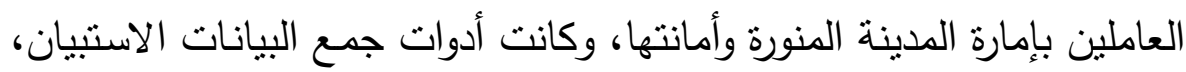
وكانت أهم النتائج قلة مستوى الإبداع الإداري، وأن الإمـارة لا تشجع الإبداع

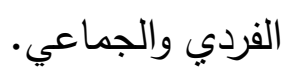
0- دراسـة "عبدالرحمن أحمد هيجـان" (999 (99) (9): بعنـوان "معوقات الإبـداع الإداري في المنظمـات السـودية" اسـتهدفت التعـرف على معوقـات الابـداع 
الإداري للمنظمـات السـودية، واسـتخدم المنهج الوصـفي، وكانـت أهـم أدوات جمع البيانات الاستبيانات، واشتملت العينة على ( • • (1) فرد من( • () وزارات

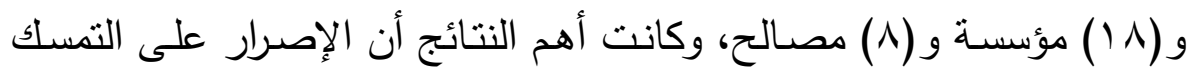

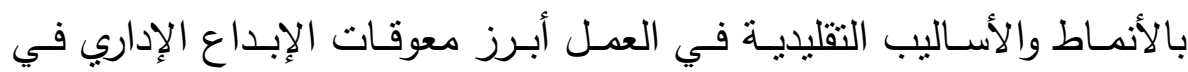

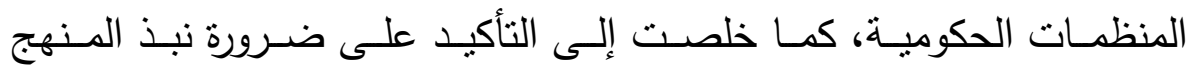
البيروقراطي كأسلوب للعمل في المنظمة. צ- دراسـة "تركي عبدالرحمن الحقباني" (999 ام) (ץ): بعنوان "أثر المتغيرات

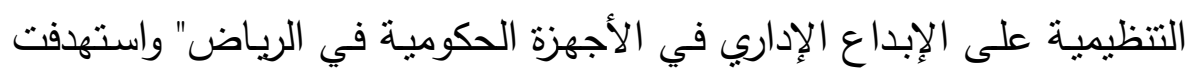
التعرف على تأثثر المتغيرات التتظيمية على مستوى الإبداع الإداري واستخدم الباحث المنهج الوصفي، وكانت أدوات جمع البيانات الاستبيانات، واشتملت

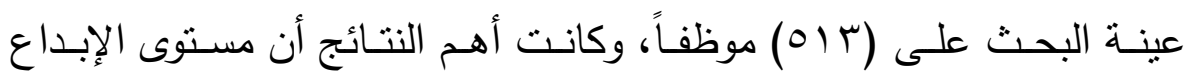
الإداري بشكل عام متوسط وأن محور الصالة جاءت نتائجه فوق المتوسط.

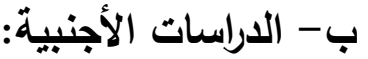

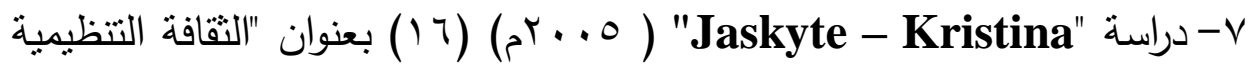
والإبداع في منظمات الخدمات الإنسانية الغير ربحية" واستهدفت التعرف علي العلاقة بين الثقافة التنظيمية والإبداع التنظيمي وذللك علي عينة من المنظمات الإنسانية، وكانت أهم النتائج التي توصل إليها الباحث هي أن المنظمة التي

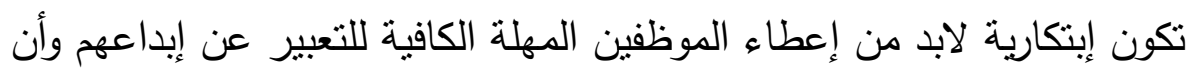

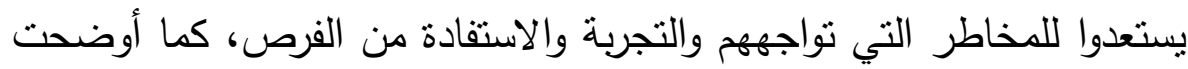
هذه الدراسة أن الثقافة التنظيمية من أهم أجهزة التتبؤ بالإبداع أو الابتكار التظظيمي لذا يجب علي القادة أن يسعوا إلي إدارة واستخدام المتغيرات الثقافية حتى تكون المنظمات منظمات إبداعية. 


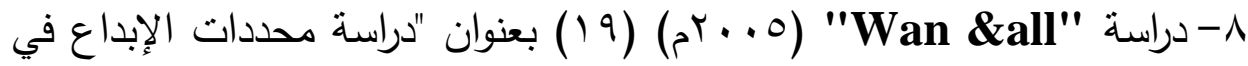

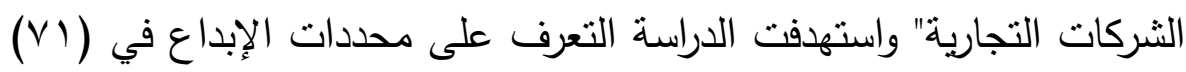
شركة في سنغافورة، واستخدم الباحث المنهج الوصفي، وكانت عينة البحث

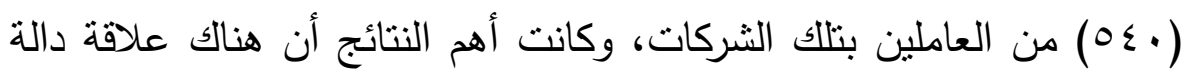
إحصائياً بين الإبداع الإداري وكلاً من الموارد التتظيمية، واعتقاد الإدارة بأهمية الإبداع، ورغبة الإدارة بتبادل أفكار الإبداع التنظيمي.

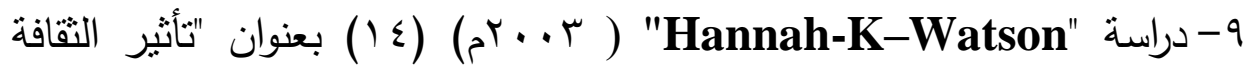
التنظيمية علي القرارات الإبداعية" واستهدفت التعرف علي مدي تبني الثقافة الجامعية فكره الإبداع وعلي نحو أكثر تحديدا عمليه تبني تكنولوجيا قاعه التدريس، واستخدم الباحث دراسة الحالة والدراسات المسحية علي عينه من (^) جامعات عامة، وكانت أهم أدوات جمع البيانات هي الاستبيان والملاحظة والوثائق الموجودة، وأهم النتائج أن الجامعات التي لديها ثقافة تتظيميه وتكنولوجيا في قاعه التدريس غالباً ما يكون لديها إبداع ولايها قياده تتبؤيه تساعد على الإبداع.

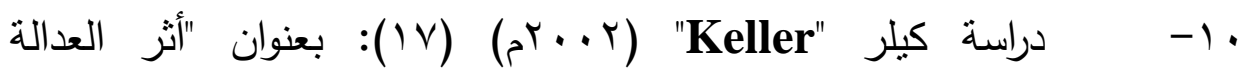
التتظيمية في الرضا الوظيفي للعاملين"، استهدفت هذه الدراسة دراسة الأثر الذي قد تحدثه العدالة التنظيمية في الرضا الوظيفي للعاملين، وهل للنوع والمستوى التتظيمي أثز في إدراك العاملين للعدالة التتظيمية ببعديها، بعينة

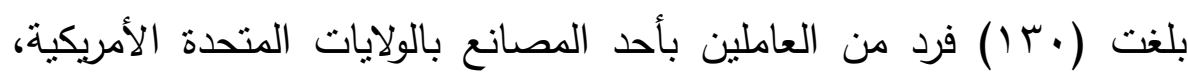
واستخدم الباحث المنهج الوصفي، وكانت أهم النتائج أن العدالة التتظيمية تؤثر بانث تأثيراً طردياً في الرضا الوظيفي.

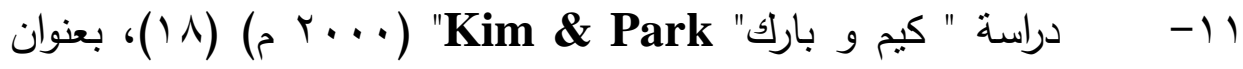

\section{Integrating Distinctive Manufacturing Competence}




\section{تأثير "Globally: Its Effect on Business Performance"}

التتسيق والتكامل في أداء الأعمال على التنافس بين الثركات العالمية"، واستهدفت الدارسة التعرف على مدي تأثير التسبيق والتكامل بين القدرات الإنتاجية المختلفة في فاعلية الأداء بالثركات متعددة الجنسيات التي تتافس عالمياً، واستخدم الباحثان المنهج التحليلي والوصفي، واشتملت عينة الدراسة على اب شركة، وكانت أهم النتائج أن مستوى المهارات والخبرات لدي ولي العاملين وسهولة انتقال المديرين أمثز تكاملاً ولها تأثير معنوى في تحقيق الفاعلية وذات ارتباط معنوي طردي بالأداء.

إجراءات البهـ : أولاً: منهج البحث :

استخدام الباحث المنهج الوصفي (الدراسات المسحية) لمناسبته لطبيعة وهدف البحث.

مجتمع وعينة البـثث :

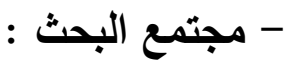

يتمنل مجتمع البحث في العاملين برعاية الطلاب لجامعة أسوان.

الأستنـتناج :

- يمكن تطوير رعاية الطلاب من خلال الأبداع الإداري من خلال الوصف

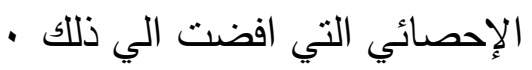

- توجد علاقة بين الأبداع الإداري والموارد التنظيمية -

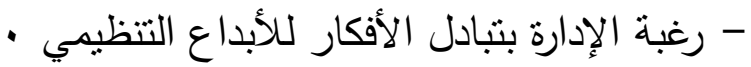

\section{التوصيات :}

- استخدام الأبداع الإداري لتطوير الأداء الإداري للعاملين برعاية الطلاب .

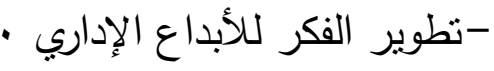


- اعتقاد الإدارة العليا بأهمية الإبداع الإداري -

\section{الـمراجr}

\section{أولاً: المراجه العربية:}

1- أحمد الخطيب رداح : الإدارة الجامعية - دراسات حديثة ، الطبعة الأولى، مؤسسة

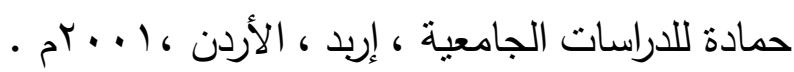

r- أسعد أحمد: أثز الثقافة التتظيمية على مستوى الأداء الوظيفي، رسالة ماجستير غير منشورة، كلية التجارة، الجامعة الإسلامية بغزة، م +. بم.

r- تركي عبدالرحمن الحقباني: أثر المتغيرات التتظيمية على الإبداع الإداري في

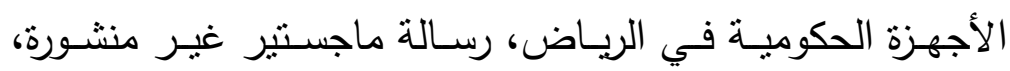

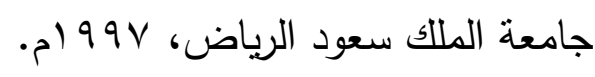

ع - حسن عبد الله باشيوة : إستشراف عناصر تفعيل إدارة مستقبل مؤسسات التعليم

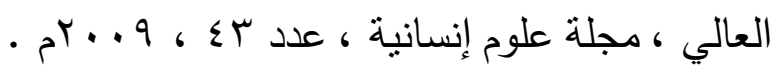

0- الا أحمد صيدلاني: المناخ التظظيمي وعلاقته بالإبداع الإداري في اتخاذ القرار

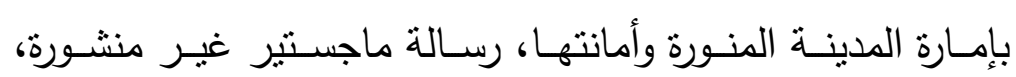

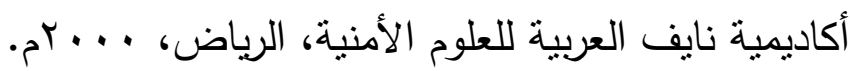

7- ـ راويـة محمـــ إدارة المـوارد البثـرية، المكتب الجـامعي الحـديث، الإسـكندرية، . $) 999$ 
- - شـامي صليحة : المنـاخ التتظيمي وتأثيره علي الأداء الوظيفي للعاملين، كليـة

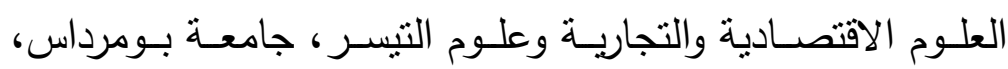

$$
\cdot r^{2} \cdot 1 \cdot
$$

1- عبد الله المهيري : الإبداع طريقك نحو قيادة المستقبل ، دار المعارف، القاهرة ،

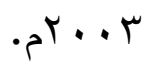

9- عبدالرحمن أحمـد هيجـان: معوقـات الإبـداع الإداري في المنظمـات السـودية،

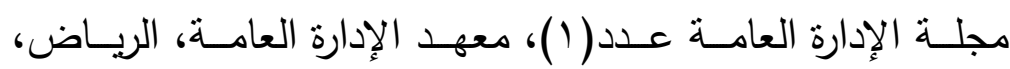

$$
\text { - }) 999
$$

• ا- عبدالرحمن أحمد هيجان: معوقات الإبداع الإداري في المنظمات السعودية، مجلة الإدارة العامة عدد( ()، معهة الإدارة العامة، الرياض، 999 إم. 99

1ا - عصام بـدوى: موسوعة التتظيم والإدارة فى التربية البدنية والرياضية، دار الفكر

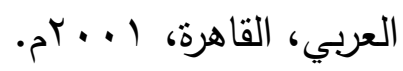

r ا - محمد الريس: أثر مقاومة التغير علي فاعلية الأداء الوظيفي بالتطبيق علي شركة العين لتوزيع الكهرباء والماء بدولة الإمارات العربية المتحدة، رسالة

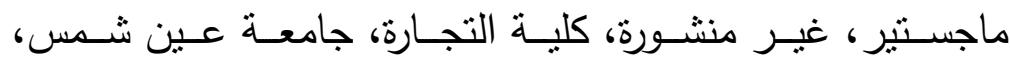

$$
\cdot r^{\prime} \cdot 0
$$

با - محمــد الصـيرفى: إدارة الأفـراد والعلاقـات الإنسـانية، طا ا، دار قنـديل للنشـر

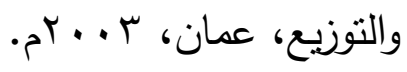


14- Hannah-K -Watson, (2003): Effects of organization culture on innovation decision :does university culture effect the ad optional of classroom technology" ।

15-

James C Becker: The important of individual performance from the perspective of gnome and ongoingational performance effectiveness "small group research" vol 32 ،2001.

16- Jaskyte - Kristina (2005): Organization Culture and innovation in nonprofit human" service Organization"

17- $\quad$ kaller: The link Between Organization Justice And Job Satisfaction Academy of Management Review ‘vol.45 2002 .

18- Kim K \& J.H. Park: "Integrating Distinctive Manufacturing `Multinational Business Review, VOL, 8 , on 1, Spring 2000.

19- Wan, D,et, al, (2005): Determinants of firms innovation in Singapore innovation. Vol. 25,N.5., pp 261- 268. 